\title{
Dual-Energy Computed Tomography Quantification of Extravasated lodine and Hemorrhagic Transformation after Thrombectomy
}

\author{
Minyoul Baik, ${ }^{\mathrm{a}, \mathrm{b}}$ Jihoon Cha, ${ }^{\mathrm{b}}$ Sung Soo Ahn, ${ }^{\mathrm{b}}$ Seung-Koo Lee, ${ }^{\mathrm{b}}$ Young Dae Kim, ${ }^{\mathrm{a}, \mathrm{c}}$ Hyo Suk Nam, ${ }^{\mathrm{a}, \mathrm{c}}$ \\ Soyoung Jeon, ${ }^{\mathrm{d}}$ Hye Sun Lee, ${ }^{\mathrm{d}}$ Ji Hoe Heo ${ }^{\mathrm{a}, \mathrm{c}}$ \\ ${ }^{a}$ Department of Neurology, Yonsei University College of Medicine, Seoul, Korea \\ ${ }^{b}$ Department of Radiology, Yonsei University College of Medicine, Seoul, Korea \\ Integrative Research Center for Cerebrovascular and Cardiovascular Diseases, Seoul, Korea \\ 'Biostatistics Collaboration Unit, Department of Research Affairs, Yonsei University College of Medicine, Seoul, Korea
}

\section{Dear Sir:}

After endovascular thrombectomy (EVT) for ischemic stroke, early prediction of hemorrhagic transformation (HT) is important because $\mathrm{HT}$ often requires changes in therapeutic strategy. ${ }^{1}$ Parenchymal hyperdense lesions, commonly observed on brain computed tomography scans after EVT, are caused by ischemic disruption of the blood-brain barrier and may be seen with secondary contrast staining or hemorrhage. ${ }^{2-4}$ Dual-energy computed tomography (DECT) can accurately differentiate hemorrhage from contrast staining, and parenchymal contrast staining has been associated with the development of future $\mathrm{HT}^{2-4}$ However, whether the predictability may be improved when both imaging and clinical markers are simultaneously considered and the imaging marker associated with HT volume remain unclear.

Hence, we aimed to identify quantified markers for iodine extravasation on early DECT for the occurrence and volume of $\mathrm{HT}$ and investigate whether the simultaneous consideration of clinical markers could improve predictability.

This single-center retrospective study included patients with acute ischemic stroke with large artery occlusion of the anterior circulation, who underwent EVT and DECT within 60 minutes after EVT between May 2019 and October 2020 (Supplementary Figure 1). The details of the study design and imaging analysis are described in the Supplementary methods and Supplementary results. ${ }^{3-18}$ Briefly, the volume of interest (VOI) was manually drawn by two independent readers. The VOls covered all areas of increased iodine concentration within the corresponding infarct territory on the iodine map of DECT. lodine concentrations were then extracted from the VOls of all images, and quantitative parameters were calculated (Figure 1). We determined the maximum iodine concentration and iodine extravasation volume that best predicted the occurrence and volume of HT, respectively (Supplementary Tables 1 and 2). HT was diagnosed and measured for volume with $\mathrm{T} 2^{*}$-weighted gradient echo (GRE) sequences 24 hours after EVT.

Of the 56 included patients, 28 (50.0\%) had HT and nine (16.1\%) had parenchymal hemorrhage (Supplementary Table 3). The mean HT volume on GRE was $6.3 \mathrm{~mL}$ (range, 0.0 to 89.6). After adjustment for clinical variables (Supplementary Table 4), the maximum iodine concentration, defined as the iodine concentration at the 95th percentile, was the best predictor of HT occurrence (odds ratio, 8.29; 95\% confidence interval, 2.30 to 29.93) (Table 1). Adding the clinical model, consisting of serum glucose level and collateral scores (Supplementary Table 4), to the maximum iodine concentration improved the prediction of $\mathrm{HT}$ occurrence, as measured using the area under the receiver operating curve ( 0.834 to $0.931, P=0.044$ ) (Supplementary Figure 2). The iodine extravasation volume, defined as the volume of iodine concentration $>0.7 \mathrm{mg} / \mathrm{mL}$, showed the best correlation with $H T$ volume $\left(\beta=0.44, R^{2}=0.791, P<0.001\right.$, Table 1; Pearson's partial correlation coefficient $r=0.823$, $P<0.001$, Supplementary Figure 3).

Herein, the maximum iodine concentration on DECT immediately after EVT was associated with HT occurrence. This find- 


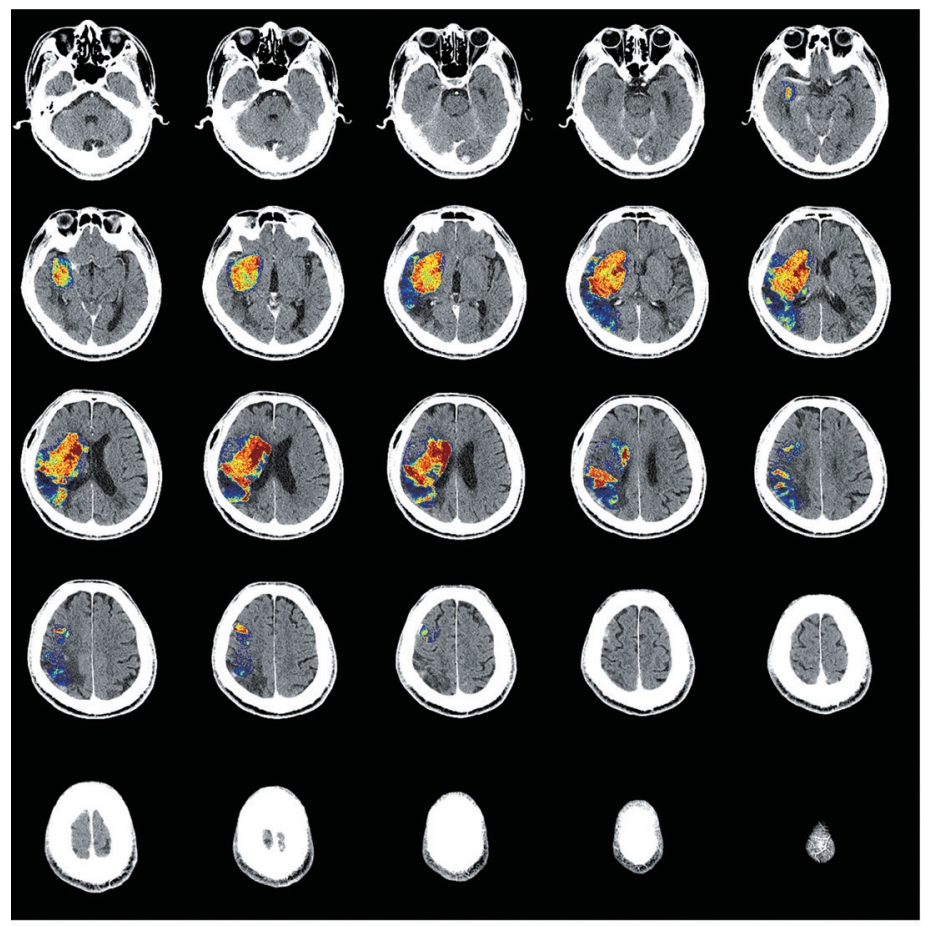

lodine concentration $>0.4 \mathrm{mg} / \mathrm{mL}$ volume: $149.98 \mathrm{~mL}$ lodine concentration $>0.7 \mathrm{mg} / \mathrm{mL}$ volume: $113.27 \mathrm{~mL}$ lodine concentration $>1.0 \mathrm{mg} / \mathrm{mL}$ volume: $90.78 \mathrm{~mL}$ lodine concentration $>1.3 \mathrm{mg} / \mathrm{mL}$ volume: $72.17 \mathrm{~mL}$ lodine concentration $>1.6 \mathrm{mg} / \mathrm{mL}$ volume: $38.69 \mathrm{~mL}$ lodine concentration $>1.9 \mathrm{mg} / \mathrm{mL}$ volume: $12.33 \mathrm{~mL}$ lodine concentration 95th percentile: $2.0 \mathrm{mg} / \mathrm{mL}$ lodine concentration 99th percentile: $2.4 \mathrm{mg} / \mathrm{mL}$ Iodine concentration 99.5th percentile: $2.6 \mathrm{mg} / \mathrm{mL}$ lodine concentration upper $1 \mathrm{~mL}$ mean: $2.87 \mathrm{mg} / \mathrm{mL}$ lodine concentration upper $0.1 \mathrm{~mL}$ mean: $3.33 \mathrm{mg} / \mathrm{mL}$
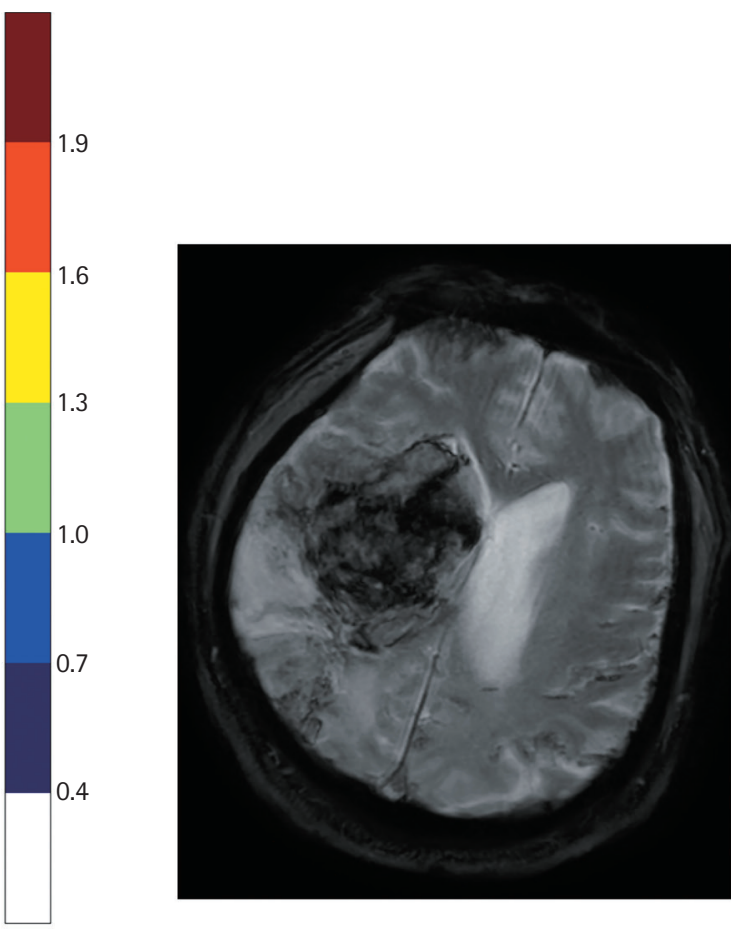

Volume of hemorrhage: $68.91 \mathrm{~mL}$

Figure 1. lodine extravasation markers on dual-energy computed tomography and comparison with gradient echo imaging.

Table 1. Multivariable regression analysis of the iodine extravasation markers

\begin{tabular}{|c|c|c|c|c|c|}
\hline & \multicolumn{2}{|c|}{ Occurrence of $\mathrm{HT}^{*}$} & \multicolumn{3}{|c|}{ Volume of $\mathrm{HT}^{+}$} \\
\hline & OR $(95 \% \mathrm{Cl})$ & $P$ & $\beta$ (SE) & $\mathrm{R}^{2}$ & $P$ \\
\hline Maximum iodine concentration ${ }^{\dagger}$ & $8.29(2.30-29.93)$ & 0.001 & $3.87(2.03)$ & 0.394 & 0.063 \\
\hline Volume of iodine extravasation ${ }^{\S}$ & $1.08(0.98-1.18)$ & 0.120 & $0.44(0.04)$ & 0.791 & $<0.001$ \\
\hline
\end{tabular}

$\mathrm{HT}$, hemorrhagic transformation; $\mathrm{OR}$, odds ratio; $\mathrm{Cl}$, confidence interval; $\mathrm{SE}$, standard error.

${ }^{*}$ Multivariable logistic regression with adjustment for variables with $P<0.05$ on the univariable analyses: serum glucose level and collateral scores; ${ }^{+} M u l t i v a r i-$ able linear regression with adjustment for variables with $P<0.05$ on the univariable analyses: diabetes, prothrombin time, National Institutes of Health Stroke Scale, and Alberta Stroke Program Early CT Score (ASPECTS); ${ }^{*}$ Maximum iodine concentration was defined as an iodine concentration at the 95th percentile; ${ }^{5} V$ olume of iodine extravasation was defined as the voxel volume with an iodine concentration $>0.7 \mathrm{mg} / \mathrm{mL}$.

ing is consistent with those of previous studies, where the maximum iodine concentration was determined in the manually defined hotspot ROI in the selected area. ${ }^{3,4}$ Using a VOIbased histogram approach, we could further reduce the potential risks of selection bias and determine the better imaging marker of iodine extravasation. ${ }^{19}$ The clinical outcomes after an EVT may be directly associated with the HT volume or parenchymal hemorrhage rather than the presence of HT itself. ${ }^{20}$ We found an independent linear correlation between the iodine extravasation volume on DECT and HT on GRE. Moreover, the 
prediction of HT improved when clinical variables were considered along with the imaging findings. Thus, it is necessary to consider both clinical factors and imaging markers when predicting HT. This study had some limitations. The sample size is small and most of the HTs in our study population had a small volume, which might limit its clinical impact.

In conclusion, the quantitative assessment of iodine extravasation on DECT immediately after EVT could help identify patients with a higher risk of HT development and a larger HT volume. Additionally, it would be beneficial to consider both clinical factors and imaging markers to predict HT.

\section{Supplementary materials}

Supplementary materials related to this article can be found online at https://doi.org/10.5853/jos.2021.03391.

\section{References}

1. Jadhav AP, Molyneaux BJ, Hill MD, Jovin TG. Care of the post-thrombectomy patient. Stroke 2018;49:2801-2807.

2. Renú $A$, Amaro $S$, Laredo $C$, Román LS, Llull L, Lopez $A$, et al. Relevance of blood-brain barrier disruption after endovascular treatment of ischemic stroke: dual-energy computed tomographic study. Stroke 2015;46:673-679.

3. Bonatti M, Lombardo F, Zamboni GA, Vittadello F, Currò Dossi $R$, Bonetti $B$, et al. lodine extravasation quantification on dual-energy CT of the brain performed after mechanical thrombectomy for acute ischemic stroke can predict hemorrhagic complications. AJNR Am J Neuroradiol 2018;39:441447.

4. Byrne D, Walsh JP, Schmiedeskamp H, Settecase F, Heran MKS, Niu B, et al. Prediction of hemorrhage after successful recanalization in patients with acute ischemic stroke: improved risk stratification using dual-energy CT parenchymal iodine concentration ratio relative to the superior sagittal sinus. AJNR Am J Neuroradiol 2020;41:64-70.

5. Powers WJ, Rabinstein AA, Ackerson T, Adeoye OM, Bambakidis NC, Becker K, et al. Guidelines for the early management of patients with acute ischemic stroke: 2019 update to the 2018 guidelines for the early management of acute ischemic stroke: a guideline for healthcare professionals from the American Heart Association/American Stroke Association. Stroke 2019;50:e344-e418.

6. Nogueira RG, Jadhav AP, Haussen DC, Bonafe A, Budzik RF, Bhuva $P$, et al. Thrombectomy 6 to 24 hours after stroke with a mismatch between deficit and infarct. N Engl J Med 2018; 378:11-21.
7. Albers GW, Marks MP, Kemp S, Christensen S, Tsai JP, Ortega-Gutierrez $S$, et al. Thrombectomy for stroke at 6 to 16 hours with selection by perfusion imaging. $N$ Engl J Med 2018;378:708-718.

8. Pasternak JJ, Williamson EE. Clinical pharmacology, uses, and adverse reactions of iodinated contrast agents: a primer for the non-radiologist. Mayo Clin Proc 2012;87:390-402.

9. Almqvist $H_{1}$ Holmin S, Mazya MV. Dual energy CT after stroke thrombectomy alters assessment of hemorrhagic complications. Neurology 2019;93:e1068-e1075.

10. Fedorov A, Beichel R, Kalpathy-Cramer J, Finet J, Fillion-Robin JC, Pujol $\mathrm{S}$, et al. 3D slicer as an image computing platform for the Quantitative Imaging Network. Magn Reson Imaging 2012;30:1323-1341.

11. Lee BI, Nam HS, Heo JH, Kim DI; Yonsei Stroke Team. Yonsei Stroke Registry. Analysis of 1,000 patients with acute cerebral infarctions. Cerebrovasc Dis 2001;12:145-151.

12. Adams HP Jr, Bendixen BH, Kappelle $\sqcup$, Biller J, Love BB, Gordon DL, et al. Classification of subtype of acute ischemic stroke. Definitions for use in a multicenter clinical trial. TOAST. Trial of Org 10172 in Acute Stroke Treatment. Stroke 1993;24:35-41.

13. Tan IY, Demchuk AM, Hopyan J, Zhang L, Gladstone D, Wong $\mathrm{K}$, et al. CT angiography clot burden score and collateral score: correlation with clinical and radiologic outcomes in acute middle cerebral artery infarct. AJNR Am J Neuroradiol 2009;30:525-531.

14. Barber PA, Demchuk AM, Zhang J, Buchan AM. Validity and reliability of a quantitative computed tomography score in predicting outcome of hyperacute stroke before thrombolytic therapy. ASPECTS Study Group. Alberta Stroke Programme Early CT Score. Lancet 2000;355:1670-1674.

15. Trouillas $P$, von Kummer R. Classification and pathogenesis of cerebral hemorrhages after thrombolysis in ischemic stroke. Stroke 2006;37:556-561.

16. DeLong ER, DeLong DM, Clarke-Pearson DL. Comparing the areas under two or more correlated receiver operating characteristic curves: a nonparametric approach. Biometrics 1988;44:837-845.

17. Pencina MJ, D'Agostino RB Sr, D'Agostino RB Jr, Vasan RS. Evaluating the added predictive ability of a new marker: from area under the ROC curve to reclassification and beyond. Stat Med 2008;27:157-172.

18. Xu C, Zhou Y, Zhang R, Chen Z, Zhong W, Gong X, et al. Metallic hyperdensity sign on noncontrast CT immediately after mechanical thrombectomy predicts parenchymal hemorrhage in patients with acute large-artery occlusion. AJNR Am J Neuroradiol 2019;40:661-667. 
19. Law $M$, Young $R$, Babb J, Pollack $E$, Johnson G. Histogram analysis versus region of interest analysis of dynamic susceptibility contrast perfusion MR imaging data in the grading of cerebral gliomas. AJNR Am J Neuroradiol 2007;28:761-766.

20. Nogueira RG, Gupta R, Jovin TG, Levy El, Liebeskind DS, Zaidat 00 , et al. Predictors and clinical relevance of hemorrhagic transformation after endovascular therapy for anterior circulation large vessel occlusion strokes: a multicenter retrospective analysis of 1122 patients. J Neurointerv Surg 2015;7:16-21.
Correspondence: Jihoon Cha

Department of Radiology, Yonsei University College of Medicine, 50-1 Yonsei-ro, Seodaemun-gu, Seoul 03722, Korea

Tel: +82-2-2228-2364

Fax: +82-2-2227-8337

E-mail: JIHOONCHA@yuhs.ac

https://orcid.org/0000-0002-1662-8041

Received: September 27, 2021

Revised: November 8, 2021

Accepted: December 23, 2021

The authors have no financial conflicts of interest. 


\section{Supplementary methods}

\section{Study design}

This study was approved by the local Institutional Review Board of Severance Hospital, Yonsei University Health System (IRB number: 4-2021-0268) with a waiver of informed consent due to the retrospective nature of this study.

First, we determined which iodine markers, including maximum iodine concentration and volume of iodine concentration, better predicted hemorrhagic transformation (HT) occurrence and volume (Supplementary Tables 1 and 2). We performed multivariable regression analysis with these iodine markers, adjusting for clinical variables, to determine correlations with HT occurrence and volume. We further investigated whether the addition of clinical variables to iodine markers could improve $\mathrm{HT}$ prediction.

\section{Recanalization treatment}

All patients underwent non-contrast computed tomography (CT), CT angiography, and CT perfusion (Revolution EVO, GE Healthcare, Milwaukee, WI, USA) at the emergency department on arrival. Patients were treated with intravenous alteplase (0.9 $\mathrm{mg} / \mathrm{kg}$ ) and/or endovascular thrombectomy (EVT) primarily based on current guidelines and recent trials..$^{5-7}$ Omnipaque (iohexol, GE Healthcare) and Visipaque (iodixanol, GE Healthcare) were used for CT angiography and catheter angiography, respectively. The devices for $\mathrm{EVT}$ included the following stent retrievers: Solitaire AB/FR (ev3, Irvine, CA, USA), Trevo Proview (Stryker, Fremont, CA, USA), Embotrap II (Neuravi, Galway, Ireland), and Aperio (Acandis, Pforzheim, Germany); and aspiration catheters, Penumbra ACE (Penumbra, Alameda, CA, USA), AXS Catalyst 6 (Stryker), and Sofia (Microvention, Tustin, CA, USA). Intra-arterial tirofiban, a glycoprotein Ilb/Illa antagonist, was used as an adjuvant therapy in cases of re-occlusion. Dual-energy computed tomography (DECT) was performed immediately after the EVT. Brain magnetic resonance imaging and magnetic resonance angiography were performed 24 hours after EVT.

\section{DECT and protocols}

The patients underwent DECT (SOMATOM Force, Siemens Healthineers, Erlangen, Germany) immediately after EVT. To minimize the time factor that affects the quantification of iodine markers, ${ }^{8,9}$ we included only patients with DECT within 60 minutes after EVT in accordance with previous studies. ${ }^{3,4}$ Non-contrast CT was performed in a dual-energy acquisition with two X-ray tubes operated at $80 \mathrm{kV}$ and $\mathrm{Sn} 150 \mathrm{kV}$, where "Sn" denotes the use of an additional tin filter that increases the mean photon energy of the respective spectrum. Scan parameters were as follows: collimation width, $192 \times 0.6 \mathrm{~mm}$; rotation time, 1.0 second; pitch, 0.7 . The effective $\mathrm{mA}$ values were set to $450 \mathrm{~mA}$ at $80 \mathrm{kV}$ and $300 \mathrm{~mA}$ at Sn150 kV. The volume CT dose index were $44.76 \mathrm{mGy}$.

During the study period, DECT data were unavailable at midnight. In addition, since the coronavirus disease 2019 (COVID-19) outbreak, patients with a body temperature of $\geq 37.3^{\circ} \mathrm{C}$, or those with any symptoms associated with COVID-19, were not allowed to move from the angiographic suite or emergency department to other areas, including the CT room for DECT, until the result of reverse transcription polymerase chain reaction test for COVID-19 was reported. As such, DECT could not be performed within 60 minutes in several patients.

\section{Image analysis of DECT}

For each patient, simulated 120-kV images, virtual non-contrast images, and iodine map images were generated using a commercially available software (syngo.via, Dual-Energy CT Brain Hemorrhage application, version VA30A, Siemens Healthineers). For quantitative image analysis, the volume of interest (VOI) was manually drawn and placed in all areas with increased concentrations on the iodine map corresponding to the infarction area. The analysis was performed using a 3D slicer (https://www.slicer.org) by two independent readers (M.B. and J.C.). ${ }^{10}$ If there was no visible area with increased iodine concentration, the ipsilateral basal ganglia were selected as the VOI. The iodine concentration within the VOls of all the images was extracted. Quantitative parameters were calculated as follows using python 3.7 (Python Software Foundation, https:// www.python.org/): volumes of iodine concentration with $>0.4$, $>0.7,>1.0,>1.3,>1.6$, and $>1.9 \mathrm{mg} / \mathrm{mL}$; iodine concentrations of 95th, 99th, and 99.5th percentile VOls; and mean iodine concentration of 0.1 and $1 \mathrm{~mL}$ with the highest iodine concentration (Figure 1). The maximum iodine concentration, volume of iodine extravasation, and volume of $\mathrm{HT}$ showed excellent reliability between the two readers (intraclass correlation coefficients of $0.92,0.97$, and 0.93 , respectively; all $>0.90$ ). The mean values recorded by the two readers were used for the statistical analysis.

\section{Clinical and imaging data}

Clinical and laboratory data were obtained from the Yonsei Stroke Registry. " Stroke subtypes, based on the Trial of ORG 10172 in the Acute Stroke Treatment classification, ${ }^{12}$ were determined at the weekly stroke conference with a consensus among stroke neurologists. The subtypes were entered into the 
registry. ${ }^{11}$ The Alberta Stroke Program Early CT Score (ASPECTS) and collateral scores proposed by Tan et al. ${ }^{13}$ were assessed on initial non-contrast $\mathrm{CT}$ and $\mathrm{CT}$ angiography. ${ }^{14} \mathrm{HT}$ was determined by the presence of any dark signal on gradient echo (GRE) images (conventional GRE sequence with $5 \mathrm{~mm}$ thickness) in the parenchyma of the corresponding infarction territory on diffusion-weighted imaging. To determine HT volume, VOls were placed in all areas with a dark signal on the GRE image in the corresponding infarction territory. Parenchymal hemorrhage was defined in accordance with the European Cooperative Acute Stroke Study II framework. ${ }^{15}$

\section{Statistical analyses}

Statistical analyses were performed using $R$ version 4.0.3 (http://www.R-project.org). Univariable analyses were performed using an independent t-test or Mann-Whitney $U$ test for continuous variables and a chi-square test for categorical variables, as appropriate. Multivariable analysis was conducted while adjusting for significant variables $(P<0.05)$ in the univariable analyses (Supplementary Table 4). The area under curves (AUCs) were compared to find which iodine marker best predicted the HT occurrence. ${ }^{16}$ Determinants for HT occurrence were studied using univariable logistic regression analyses. AUCs were calculated to determine whether the addition of the clinical variables to DECT variables could improve HT prediction. ${ }^{17}$ We examined the correlation between the iodine markers and the HT volume using correlation coefficients and compared them using the Steigers Z-test. We calculated the univariable linear regression $\beta$ coefficients, standard errors, $R^{2}$, and $P$-values to identify variables related to $H T$ volume. Multivariable linear regression analysis was used to determine the independent correlates of the HT volume. To assess the association between HT volume and iodine markers, Pearson's partial correlation analyses were performed between $\mathrm{HT}$ volume and maximum iodine concentration or the volume of iodine extravasation. Statistical significance was set at $P<0.05$.

\section{Supplementary results}

\section{Conventional method and VOI-based histogram method}

We compared the predictability of the occurrence of HT between the VOI-based histogram method (maximum iodine concentration on DECT) and the conventional method (metallic hyperdensity sign on non-contrast brain CT). ${ }^{16}$ The metallic hyperdensity sign was defined as a non-petechial intracerebral hyperdense lesion (diameter, $\geq 1 \mathrm{~cm}$ ) in the basal ganglia and a maximum density of $>90$ hounsfield unit $(\mathrm{HU})$ on simulated 120-kV images of DECT. ${ }^{18}$ Maximum iodine concentration better predicted the occurrence of future $\mathrm{HT}$ than the conventional metallic hyperdensity sign (AUCs 0.834 vs. $0.732, P=0.044$ ). 
Supplementary Table 1. AUC comparison for occurrence of hemorrhagic transformation

\begin{tabular}{llc}
\hline Variable & AUC (95\% Cl) & $P$ \\
\hline Maximum iodine concentration & & Ref \\
lodine concentration of $95 \%$ & $0.834(0.726-0.943)$ & 0.181 \\
lodine concentration of $99 \%$ & $0.809(0.693-0.925)$ & 0.109 \\
lodine concentration of $99.5 \%$ & $0.791(0.668-0.914)$ & 0.501 \\
Mean iodine concentration of upper $1 \mathrm{~mL}$ & $0.817(0.702-0.931)$ & 0.204 \\
Mean iodine concentration of upper $0.1 \mathrm{~mL}$ & $0.796(0.675-0.917)$ & 0.130 \\
Volume of iodine extravasation & & 0.376 \\
Volume of iodine concentration $>0.4 \mathrm{mg} / \mathrm{mL}$ & $0.751(0.621-0.882)$ & 0.403 \\
Volume of iodine concentration $>0.7 \mathrm{mg} / \mathrm{mL}$ & $0.800(0.683-0.918)$ & 0.161 \\
Volume of iodine concentration $>1.0 \mathrm{mg} / \mathrm{mL}$ & $0.809(0.696-0.922)$ & $0.783(0.656-0.909)$ \\
Volume of iodine concentration $>1.3 \mathrm{mg} / \mathrm{mL}$ & $0.795(0.672-0.917)$ & $0.804(0.689-0.919)$ \\
Volume of iodine concentration $>1.6 \mathrm{mg} / \mathrm{mL}$ & & 0.401 \\
Volume of iodine concentration $>1.9 \mathrm{mg} / \mathrm{mL}$ & & 0.726 to \\
\hline
\end{tabular}

The maximum iodine concentration was defined as the iodine concentration at the 95th percentile because the AUC $(0.834 ; 95 \% \mathrm{Cl}, 0.726$ to 0.943$)$ tended to be higher than that of other iodine concentrations. A cut-off value of $1.70 \mathrm{mg} / \mathrm{mL}$ allowed us to identify patients who developed hemorrhagic transformation with $67.9 \%$ sensitivity and $89.3 \%$ specificity.

$\mathrm{AUC}$, area under curve; $\mathrm{Cl}$, confidence interval.

Supplementary Table 2. Correlation coefficient comparison for volume of hemorrhagic transformation

\begin{tabular}{|c|c|c|}
\hline Variable & $\mathrm{R}(95 \% \mathrm{Cl})$ & $P$ \\
\hline \multicolumn{3}{|l|}{ Maximum iodine concentration } \\
\hline lodine concentration of 95\% & $0.391(0.142-0.593)$ & $<0.001$ \\
\hline lodine concentration of $99 \%$ & $0.376(0.125-0.581)$ & $<0.001$ \\
\hline lodine concentration of $99.5 \%$ & $0.403(0.157-0.602)$ & $<0.001$ \\
\hline Mean iodine concentration of upper $1 \mathrm{~mL}$ & $0.577(0.370-0.729)$ & $<0.001$ \\
\hline Mean iodine concentration of upper $0.1 \mathrm{~mL}$ & $0.569(0.360-0.724)$ & $<0.001$ \\
\hline \multicolumn{3}{|l|}{ Volume of iodine extravasation } \\
\hline Volume of iodine concentration $>0.4 \mathrm{mg} / \mathrm{mL}$ & $0.830(0.726-0.897)$ & 0.136 \\
\hline Volume of iodine concentration $>0.7 \mathrm{mg} / \mathrm{mL}$ & $0.845(0.749-0.907)$ & Ref \\
\hline Volume of iodine concentration $>1.0 \mathrm{mg} / \mathrm{mL}$ & $0.819(0.709-0.890)$ & 0.013 \\
\hline Volume of iodine concentration $>1.3 \mathrm{mg} / \mathrm{mL}$ & $0.774(0.642-0.862)$ & $<0.001$ \\
\hline Volume of iodine concentration $>1.6 \mathrm{mg} / \mathrm{mL}$ & $0.699(0.534-0.812)$ & $<0.001$ \\
\hline Volume of iodine concentration $>1.9 \mathrm{mg} / \mathrm{mL}$ & $0.597(0.397-0.743)$ & $<0.001$ \\
\hline
\end{tabular}

The correlation coefficient between the volume of iodine concentration $>0.7 \mathrm{mg} / \mathrm{mL}$ and the hemorrhagic transformation volume was higher than that of other iodine volume parameters. Hence, voxels with an iodine concentration $>0.7 \mathrm{mg} / \mathrm{mL}$ were used to determine the volume of iodine extravasation. $\mathrm{Cl}$, confidence interval. 
Supplementary Table 3. Demographic characteristics of patients stratified by hemorrhagic transformation

\begin{tabular}{|c|c|c|c|}
\hline \multirow{2}{*}{ Characteristic } & \multicolumn{2}{|c|}{ Hemorrhagic transformation } & \multirow{2}{*}{$P$} \\
\hline & Yes $(n=28)$ & No $(n=28)$ & \\
\hline \multicolumn{4}{|l|}{ Medical history } \\
\hline Age (yr) & $72.0 \pm 14.8$ & $69.6 \pm 13.0$ & 0.530 \\
\hline Male sex & $20(71.4)$ & $15(53.6)$ & 0.270 \\
\hline Hypertension & $21(75.0)$ & $21(75.0)$ & $>0.999$ \\
\hline Diabetes mellitus & $15(53.6)$ & $9(32.1)$ & 0.177 \\
\hline Dyslipidemia & $8(28.6)$ & $11(39.3)$ & 0.572 \\
\hline Old stroke & $6(21.4)$ & $7(25.0)$ & $>0.999$ \\
\hline Ischemic heart disease & $6(21.4)$ & $3(10.7)$ & 0.467 \\
\hline Peripheral artery occlusive disease & $2(7.1)$ & $3(10.7)$ & $>0.999$ \\
\hline Current smoker & $7(25.0)$ & $5(17.9)$ & 0.745 \\
\hline Atrial fibrillation & $15(53.6)$ & $15(53.6)$ & $>0.999$ \\
\hline Prior antithrombotics use & $16(57.1)$ & $10(35.7)$ & 0.180 \\
\hline Antiplatelet agents & $12(42.9)$ & $5(17.9)$ & 0.081 \\
\hline Anticoagulants & $7(25.0)$ & $6(21.4)$ & $>0.999$ \\
\hline Pre-mRS & $0.0(0.0-0.0)$ & $0.0(0.0-0.5)$ & 0.756 \\
\hline Pre-mRS $\leq 2$ & $27(96.4)$ & 26 (92.9) & $>0.999$ \\
\hline Initial SBP (mm Hg) & $159.1 \pm 30.0$ & $148.9 \pm 27.5$ & 0.187 \\
\hline \multicolumn{4}{|l|}{ Laboratory findings } \\
\hline Platelet counts $\left(\times 10^{9} / \mathrm{L}\right)$ & $230.2 \pm 72.6$ & $236.0 \pm 81.4$ & 0.777 \\
\hline PT, INR & $1.0(1.0-1.1)$ & $1.0(1.0-1.1)$ & $>0.999$ \\
\hline aPTT (sec) & $29.1(27.5-32.5)$ & $29.0(27.1-31.9)$ & 0.676 \\
\hline Serum glucose $(\mathrm{mmol} / \mathrm{L})$ & $8.3(6.4-11.0)$ & $6.5(5.7-7.6)$ & 0.009 \\
\hline eGFR $\left(\mathrm{mL} / \mathrm{min} / 1.73 \mathrm{~m}^{2}\right)$ & $75.6 \pm 21.6$ & $81.9 \pm 17.0$ & 0.237 \\
\hline \multicolumn{4}{|l|}{ Stroke characteristics } \\
\hline Initial NIHSS & $12.0 \pm 6.4$ & $11.9 \pm 7.4$ & 0.954 \\
\hline ASPECTS & $7.5(6.0-9.0)$ & $9.0(8.0-9.0)$ & 0.071 \\
\hline ASPECTS $\geq 6$ & 25 (89.3) & 26 (92.9) & $>0.999$ \\
\hline Collateral scores & $1.0(1.0-2.0)$ & $2.0(1.5-2.0)$ & 0.003 \\
\hline Collateral score $\geq 2$ & 11 (39.3) & $21(75.0)$ & 0.015 \\
\hline TOAST CE (vs. non-CE) & $18(64.3)$ & $13(46.4)$ & 0.282 \\
\hline TOAST & & & 0.175 \\
\hline $\mathrm{CE}$ & $18(64.3)$ & $13(46.4)$ & \\
\hline LAA & $6(21.4)$ & $6(21.4)$ & \\
\hline Other determined & $2(7.1)$ & $1(3.6)$ & \\
\hline Undetermined & $2(7.1)$ & $3(10.7)$ & \\
\hline More than two causes & $0(0)$ & $5(17.9)$ & \\
\hline IV-tPA & $12(42.9)$ & $10(35.7)$ & 0.784 \\
\hline IA-tirofiban & $4(14.3)$ & $4(14.3)$ & $>0.999$ \\
\hline No. of stent retriever passes & $1.0(1.0-2.0)$ & $1.0(1.0-2.0)$ & 0.796 \\
\hline Onset to puncture (min) & 335.0 (190.5-717.0) & $304.5(201.5-596.5)$ & 0.954 \\
\hline $\mathrm{TICl}$ grade 3 & $16(57.1)$ & $18(64.3)$ & 0.784 \\
\hline \multicolumn{4}{|l|}{ Imaging characteristics } \\
\hline Closing to DECT (min) & $24.0(19.5-34.0)$ & $25.0(19.5-29.5)$ & 0.737 \\
\hline Closing to MRI (hr) & $13.5(11.0-16.0)$ & $14.0(12.0-18.0)$ & 0.444 \\
\hline \multicolumn{4}{|l|}{ Outcome variables } \\
\hline $\mathrm{mRS}$ at discharge & $4.5(2.0-5.0)$ & $2.5(1.0-5.0)$ & 0.083 \\
\hline $\mathrm{mRS}$ at discharge $\leq 2$ & $9(32.1)$ & $14(50.0)$ & 0.277 \\
\hline$m R S$ at 3 months $(n=52)$ & $3.0(1.0-6.0)$ & $2.0(0.5-4.0)$ & 0.257 \\
\hline$m R S$ at 3 months $\leq 2(n=52)$ & $12(48.0)$ & $14(51.9)$ & $>0.999$ \\
\hline
\end{tabular}

Values are presented as mean \pm standard deviation, number $(\%)$, or median (interquartile range).

mRS, modified Rankin Scale; SBP, systolic blood pressure; PT, prothrombin time; INR, international normalized ratio; aPT, activated partial thromboplastin time; eGFR, estimated glomerular filtration rate; NIHSS, National Institutes of Health Stroke Scale; ASPECTS, Alberta Stroke Program Early CT Score; TOAST, Trial of ORG 10172 in Acute Stroke Treatment; CE, cardioembolism; LAA, large artery atherosclerosis; IV, intravenous; tPA, tissue plasminogen activator; IA, intra-arterial; $\mathrm{TICl}$, thrombolysis in cerebral infarction; DECT, dual-energy computed tomography; MRI, magnetic resonance imaging. 
Supplementary Table 4. Univariable regression analysis

\begin{tabular}{|c|c|c|c|c|}
\hline \multirow{2}{*}{ Variable } & \multicolumn{2}{|c|}{ Occurrence of hemorrhagic transformation } & \multicolumn{2}{|c|}{ Volume of hemorrhagic transformation } \\
\hline & OR $(95 \% \mathrm{Cl})$ & $P$ & $\beta$ (SE) & $P$ \\
\hline \multicolumn{5}{|l|}{ Medical history } \\
\hline Age (yr) & $1.01(0.97-1.05)$ & 0.523 & $0.05(0.17)$ & 0.755 \\
\hline Male sex & $2.17(0.73-6.77)$ & 0.171 & $-0.48(4.92)$ & 0.923 \\
\hline Hypertension & $1.00(0.29-3.41)$ & $>0.999$ & $7.31(5.42)$ & 0.183 \\
\hline Diabetes mellitus & $2.44(0.84-7.45)$ & 0.108 & $11.57(4.55)$ & 0.014 \\
\hline Dyslipidemia & $0.62(0.20-1.88)$ & 0.399 & $-6.43(4.96)$ & 0.200 \\
\hline Old stroke & $0.82(0.23-2.86)$ & 0.752 & $5.48(5.60)$ & 0.332 \\
\hline Ischemic heart disease & $2.27(0.53-11.79)$ & 0.283 & $6.39(6.43)$ & 0.325 \\
\hline Peripheral artery occlusive disease & $0.64(0.08-4.18)$ & 0.641 & $7.30(8.30)$ & 0.383 \\
\hline Current smoker & $1.53(0.42-5.89)$ & 0.516 & $-6.26(5.75)$ & 0.281 \\
\hline Atrial fibrillation & $1.00(0.35-2.88)$ & $>0.999$ & $2.37(4.77)$ & 0.622 \\
\hline Prior antithrombotics use & $2.40(0.83-7.24)$ & 0.111 & $4.41(4.74)$ & 0.357 \\
\hline Initial SBP (mm Hg) & $1.01(0.99-1.03)$ & 0.187 & $0.10(0.08)$ & 0.246 \\
\hline \multicolumn{5}{|l|}{ Laboratory findings } \\
\hline Platelet counts $\left(\times 10^{9} / \mathrm{L}\right)$ & $1.00(0.99-1.00)$ & 0.773 & $-0.02(0.03)$ & 0.630 \\
\hline PT, INR & $3.14(0.93-130.42)$ & 0.307 & $3.55(1.73)$ & 0.044 \\
\hline aPTT (sec) & $1.06(0.94-1.22)$ & 0.333 & $-0.13(0.54)$ & 0.814 \\
\hline Serum glucose (mmol/L) & $1.40(1.09-1.94)$ & 0.023 & $0.96(0.61)$ & 0.118 \\
\hline eGFR $\left(\mathrm{mL} / \mathrm{min} / 1.73 \mathrm{~m}^{2}\right)$ & $0.98(0.95-1.01)$ & 0.236 & $-0.16(0.12)$ & 0.189 \\
\hline \multicolumn{5}{|l|}{ Stroke characteristics } \\
\hline Initial NIHSS & $1.00(0.93-1.08)$ & 0.953 & $0.69(0.34)$ & 0.044 \\
\hline ASPECTS & $0.73(0.51-1.01)$ & 0.070 & $-5.02(1.16)$ & $<0.001$ \\
\hline ASPECTS $\geq 6$ & $0.64(0.08-4.18)$ & 0.641 & & \\
\hline Collateral scores & $0.22(0.07-0.58)$ & 0.004 & $-7.13(3.74)$ & 0.062 \\
\hline Collateral score $\geq 2$ & $0.22(0.07-0.65)$ & 0.009 & & \\
\hline TOAST CE (vs. non-CE) & $2.08(0.72-6.22)$ & 0.181 & $6.93(4.70)$ & 0.147 \\
\hline IV-tPA & $1.35(0.46-4.02)$ & 0.585 & $-6.78(4.79)$ & 0.163 \\
\hline IA-tirofiban & $1.00(0.21-4.68)$ & $>0.999$ & $-0.65(6.81)$ & 0.924 \\
\hline No. of stent retriever passes & $0.86(0.49-1.48)$ & 0.588 & $-0.82(2.43)$ & 0.737 \\
\hline Onset to puncture (min) & $1.00(1.00-1.00)$ & 0.546 & $0.00(0.00)$ & 0.623 \\
\hline $\mathrm{TICl}$ grade 3 & $0.74(0.25-2.17)$ & 0.585 & $2.10(4.87)$ & 0.669 \\
\hline \multicolumn{5}{|l|}{ Imaging characteristics } \\
\hline Closing to DECT (min) & $1.01(0.96-1.06)$ & 0.699 & $0.24(0.22)$ & 0.283 \\
\hline Closing to MRI (hr) & $0.97(0.91-1.02)$ & 0.287 & $-0.16(0.21)$ & 0.461 \\
\hline \multicolumn{5}{|l|}{ lodine markers } \\
\hline Maximum iodine concentration & $6.21(2.28-16.92)$ & $<0.001$ & $6.45(2.07)$ & 0.003 \\
\hline Volume of iodine extravasation & $1.09(1.00-1.18)$ & 0.050 & $0.48(0.04)$ & $<0.001$ \\
\hline
\end{tabular}

Among the clinical variables, the serum glucose level at admission and collateral scores were associated with the occurrence of hemorrhagic transformation $(\mathrm{HT})$ in univariable logistic regression analyses. The maximum iodine concentration was associated with HT occurrence, whereas the volume of iodine extravasation was not. In the univariable linear regression analyses, HT volume was associated with diabetes, prothrombin time, NIHSS score, ASPECTS score, maximum iodine concentration, and volume of iodine extravasation.

$\mathrm{OR}$, odds ratio; $\mathrm{Cl}$, confidence interval; SE, standard error; SBP, systolic blood pressure; PT, prothrombin time; INR, international normalized ratio; aPTT, activated partial thromboplastin time; eGFR, estimated glomerular filtration rate; NIHSS, National Institutes of Health Stroke Scale; ASPECTS, Alberta Stroke Program Early CT Score; TOAST, Trial of ORG 10172 in acute stroke treatment; CE, cardioembolism; IV, intravenous; tPA, tissue plasminogen activator; IA, intra-arterial; $\mathrm{TICl}$, thrombolysis in cerebral infarction; DECT, dual-energy computed tomography; MRI, magnetic resonance imaging. 


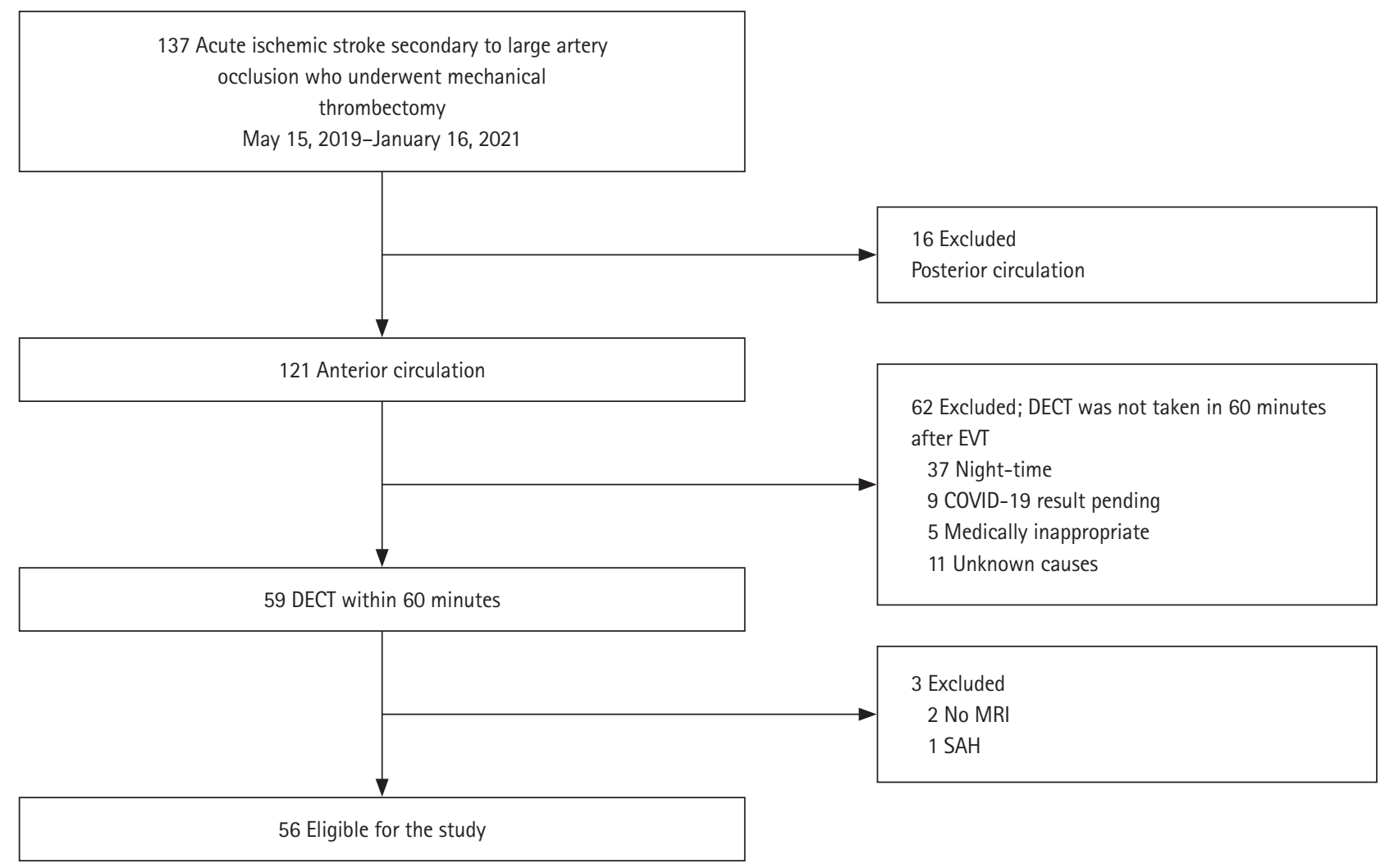

Supplementary Figure 1. Patient selection. DECT, dual-energy computed tomography; EVT, endovascular thrombectomy; COVID-19, coronavirus disease 2019; MRI, magnetic resonance imaging; SAH, subarachnoid hemorrhage. 


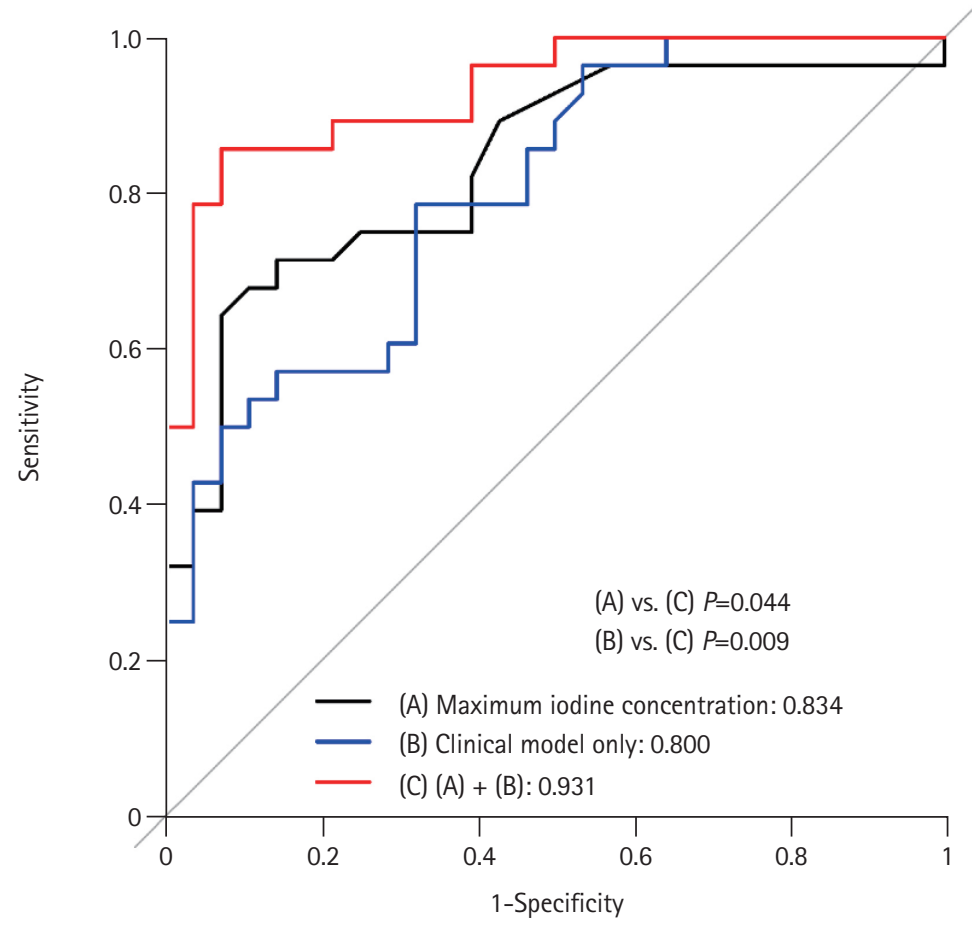

Supplementary Figure 2. Additive predictive value of maximum iodine concentration on dual-energy computed tomography after endovascular thrombectomy for ischemic stroke measured by comparison of area under curve (AUC). We evaluated whether hemorrhagic transformation (HT) prediction was improved by adding a clinical model consisting of serum glucose levels and collateral scores to the maximum iodine concentration. The AUC for HT occurrence was 0.800 (95\% confidence interval [Cl], 0.687 to 0.914$)$ for the clinical model and $0.834(95 \% \mathrm{Cl}, 0.726$ to 0.943$)$ for the maximum iodine concentration alone. When both the clinical model and maximum iodine concentration were considered, the AUC increased to $0.931(95 \% \mathrm{Cl}, 0.867$ to $0.995 ; P=0.044)$, with $85.7 \%$ sensitivity and $92.9 \%$ specificity. 


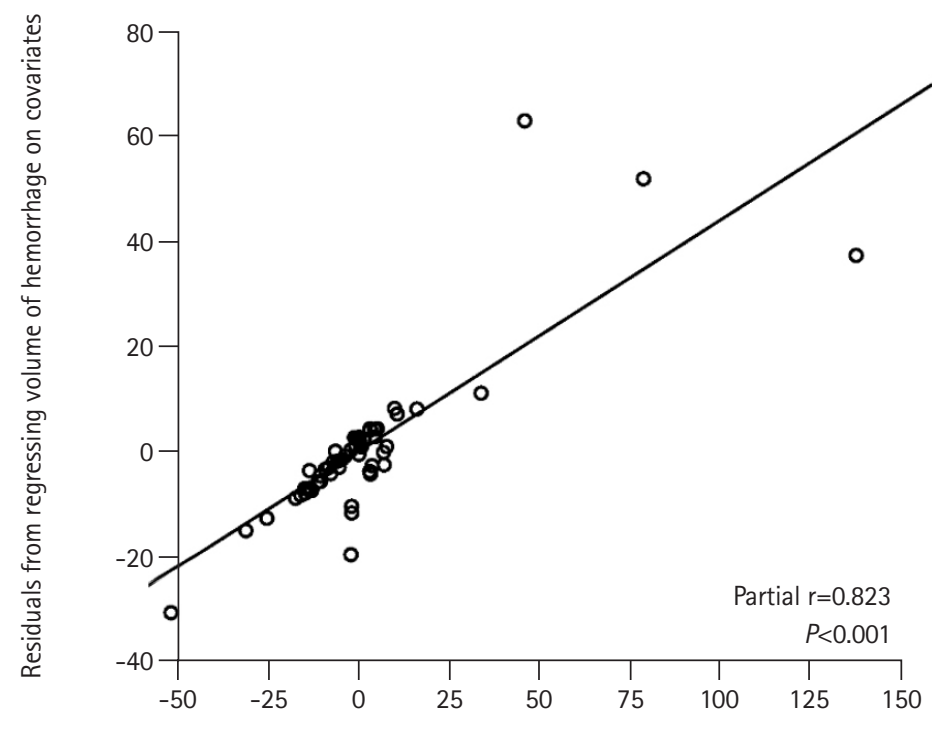

Residuals from regressing volume of iodine extravasation on covariates

Supplementary Figure 3. Relationship between volume of hemorrhagic transformation and volume of iodine extravasation on dual-energy computed tomography after endovascular thrombectomy for ischemic stroke measured by Pearson's partial correlation coefficient after adjusting for clinical variables. The volume of iodine extravasation showed a significant correlation with the hemorrhagic transformation (HT) volume after adjusting for clinical variables; diabetes, prothrombin time, National Institutes of Health Stroke Scale (NIHSS), Alberta Stroke Program Early CT Score (ASPECTS) (partial $r=0.823, P<0.001)$. However, the maximum iodine concentration was not correlated (Pearson's partial correlation coefficient $r=0.260, P=0.063$ ) with the HT volume. The $y$-axes are based on the calculated residuals from regressing hemorrhage volume on diabetes, prothrombin time, NIHSS, and ASPECTS. The x-axes are based on the calculated residuals from the regressing volume of iodine extravasation on diabetes, prothrombin time, NIHSS, and ASPECTS. $r$ Pearson's partial correlation coefficient ( $r=0$, no linear relationship; $r=1$ or -1 , perfect linear relationship). 